\title{
0 rosto do ator: da expressão fotogênica ao reflexo externo
}

The actor's face: from the photogenic expression to the external reflection

\section{Pedro Maciel Guimarães}

Pedro Maciel Guimarães

Professor do Departamento de Cinema do Instituto de Artes da Unicamp

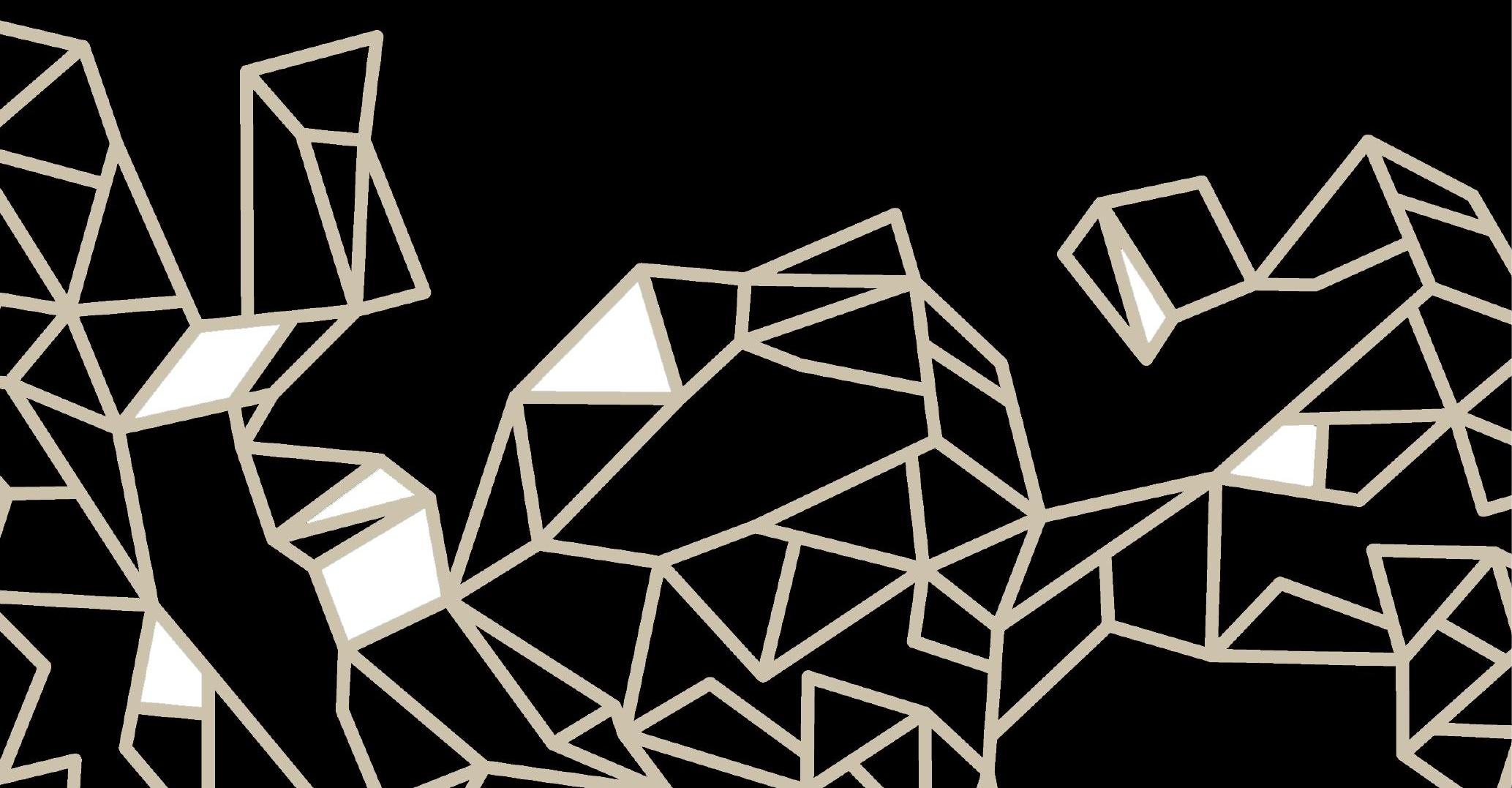




\section{Resumo}

Os usos e as teorias em torno da composição em primeiro plano, que coloca em destaque o rosto do ator: da ideia de fotogenia e da emoção facilmente visível na face atoral, defendida por Louis Delluc e Jean Epstein, passando pelos conceitos de rosto-máscara e rosto-máquina de Lev Kulechov e Mikhail lampolski, ligados às vanguardas soviéticas dos anos 1920, até a proposta de Jacques Aumont para analisar os closes das atrizes do cinema clássico e moderno, que se dividem em rosto-alma e rosto-tela.

Palavras-chave: Atores de cinema, Estética e história do cinema, Análise fílmica.

\section{Abstract}

The uses and theories around the composition in the foreground, which puts emphasis on the actor's face: the idea of photogenic and visible emotion from Louis Delluc and Jean Epstein; Lev Kulechov and Mikhail lampolski's mask face and machine face, linked to the Soviet avant-garde of the 1920s; Jacques Aumont's proposition to analyze the close-up of actresses of the classic and modern cinema, divided into "soul face" and "screen face".

Keywords: Film actors, Aesthetics and history of cinema, Film analysis.

No teatro ou no cinema, o corpo é a superfície comunicante e significante mais eficaz e facilmente quantificável e analisável do trabalho do ator. No corpo, o rosto surge como local nobre de veiculação de afetos, sentimentos e emoções. Para além das diferenças de postura e estilo entre atuação para o cinema e para o teatro, as particularidades da linguagem cinematográfica, que prevê que a câmera se aproxime do corpo do intérprete, quebrando a continuidade espacial verossímil para apresentar o rosto em close, separam definitivamente jogo cinematográfico e jogo teatral.

A compreensão do rosto do ator no cinema evoluiu dentro das perspectivas estéticas e tecnológicas do meio, tendo por isso, assim como outros elementos da mise-en-scène, suas definições e representações modificadas ao longo da história. Estudaremos aqui a atuação do ator e sua relação com 
o espectador e o dispositivo quando este se coloca em primeiro plano, face engrandecida pela câmera e corpo excluído da representação. Se o close limita a possibilidade de atuação ampla ao excluir membros e tronco como superfícies significantes, ele abre outras portas de percepção, que incluem a significação psicológica e a atenção aos detalhes, principalmente do olhar e dos elementos ínfimos da expressão facial.

O rosto do ator teve três grandes tempos e teorias: a era da fotogenia, conceito que abarca grande variedade temporal e representativa, e as eras das dicotomias "máquina-máscara" e "alma-tela". A fotogenia destaca-se por aparecer como um conceito-chave, ligado inicialmente às vanguardas europeias dos anos 1920, mas que volta retrabalhada em diferentes períodos históricos. Na época do cinema silencioso e início da fase falada do clássico (final dos anos 1920 até os 1940), a fotogenia funciona como pilar econômico do cinema industrial e elemento preponderante de alguns gêneros, como melodrama ou horror. Para os cineastas modernos, a partir dos anos 1950, a fotogenia do rosto em close serve como rede de perturbações estéticas que buscam fugir da representação unicamente psicológica ou afetiva.

Por outro lado, a dualidade "rosto-máquina" e "rosto-máscara" foi teorizada por Mikhail lampolski para falar do cinema soviético dos anos 1920-1930. Não representando necessariamente uma dicotomia (eles não se opõem, a não ser na maneira como usam os movimentos das partes do rosto para significar), as formas da máscara e da máquina aparecem também retrabalhadas no cinema moderno pós-Nouvelle Vague. Ambos se opõem ao "rosto-expressão" ou "rosto-sentimento", numa dualidade que pode ser resumida como "maquinismo contra organicidade".

Nos anos 1990, a teorização que opõe "rosto-alma" e "rosto-tela" foi proposta por Jacques Aumont, servindo como um compêndio das posições teóricas tomadas pelas diferentes abordagens da individualidade, do jogo e dos afetos transmitidos pela face atoral. De um lado, tem-se o rosto como local de expressão nobre do trabalho do ator, num processo de exteriorização dos sentimentos através dos gestos que remete ao jogo teatral e cuja representação se complexifica pela possibilidade de a face aparecer monumental na tela do cinema. Do outro, o rosto usado como um mero envelope, um receptáculo 
que não prevê, necessariamente, uma interioridade e que foca a atenção na reflexividade exterior, na superfície e na descontinuidade.

\section{Fotogenia: emoção e projeção}

Trata-se de conceito amplamente banalizado pela linguagem cotidiana sobre uma suposta harmonia física de traços do rosto em fotografias e filmes, em sua maioria amadores. A fotogenia pertence, no entanto, a um quadro teórico bem definido no qual a beleza plástica nem sempre tem a palavra final. Ela pode ser resumida como o efeito quase miraculoso que a visão aproximada do rosto desencadeia nos espectadores, mesclando admiração, inquietação, fascínio e êxtase. A fotogenia pode atingir também objetos ou partes do corpo em close. Nesse caso, ela revela atributos expressivos e significativos da coisa representada para além da denotação de sua aparência.

A busca pela fotogenia é o ponto nevrálgico da construção da imagem do cinema clássico, a mola-mestra do jogo naturalista do ator, da identificação entre espectador e personagem e do sistema de estrelato dos estúdios hollywoodianos. Sua conceituação se produziu, no entanto, na Europa do cinema de vanguarda, que agia contra o domínio da forma industrial de Hollywood. Preocupação comum de cineastas vanguardistas franceses como Germaine Dulac, Abel Gance, Louis Delluc, e também do russo Lev Kulechov, o termo aparece pela primeira vez nos escritos de Epstein em Bonjour Cinéma (1921).

Para Epstein, existe uma qualidade moral dos seres e das coisas que é revelada somente pela reprodução cinematográfica. Ou seja, no cinema, as coisas e as pessoas mostram algo do registro do sublime, do divino ou da revelação psíquica de expressões e sentimentos. Um rosto visto a olho nu, ou visto numa pintura ou no teatro, não expressa as mesmas coisas que enquadrado bem de perto pela câmera. O cinema, máquina de pensar o tempo segundo Epstein, leva as coisas a aparecer de maneira singular, epifânica, dependendo de como são enquadradas, iluminadas e inscritas num avançar temporal - a ideia de fotogenia de Epstein era ligada ao uso da câmera lenta, que representa "um ganho de qualidade moral" (apud AUMONT, 1992, p. 90). 
Nesse sentido, o rosto do ator foi a superfície sobre a qual o conceito de fotogenia se desenvolveu mais amplamente, mas não apenas nele; falou-se de fotogenia das imagens de mãos, de outras partes do corpo e até de objetos inanimados. Para Epstein, o close era o cerne do cinema. Falando sobre o cinema americano da época, sentencia:

Nunca encontrei palavras certas para dizer como me fascinam os close-ups do cinema norte-americano... Repentinamente, um rosto surge na tela e o drama, agora frente a frente, parece se dirigir pessoalmente a mim, assumindo extraordinária intensidade. (EPSTEIN, 1977, p. 9)

Nos primeiros escritos de Epstein e seus colegas, destacam-se algumas características que serão a base do conceito de fotogenia. Primeiro, a valorização do elemento moral do cinema, capaz de revelar prerrogativas ligadas a uma elevação espiritual dos seres ou da coisa fotografada. Sobre esse elemento moral se apoiaram tanto os planos precursores do primeiro cinema de Chaplin e Griffith quanto os gêneros focados na elevação sentimental dos personagens (melodramas e dramas românticos) da época do cinema clássico até o cinema moderno de Rossellini ou Godard, na sua fascinação pelo rosto de atrizes. O rosto expressivamente fotogênico propaga a ideia de que o gesto do ator serve para expressar seu estado de espírito. Os movimentos do rosto fotogênico, por mais ínfimos que sejam, dão conta de uma condição emocional e psicológica que o ator/personagem sente no seu íntimo e expressa através de elementos do rosto (olhos, boca, nariz, sobrancelhas).

O gesto do ator aparece então como base da relação de identificação entre ator/personagem e espectador e como elemento de manifestação dos afetos: os atos de chorar, gritar, clamar, respirar ofegantemente são facilmente identificados como prolongamentos dos sentimentos experimentados na vida (naturalistas, portanto) e compreendidos pelo espectador pelo viés psicológico (“o personagem está desesperado", "ele está apaixonado"). Courtine e Haroche (2007) pregam que o estudo do rosto é necessário para se

entender as mutações da figura do homem: a figura e a representação (discursiva e icônica) do homem interior (paixões, vícios, virtudes, emoções) através de um conjunto de índices corporais e exteriores (formas, marcas, rastros, traços, signos). (p. 43) 
Dito de outro modo, o externo explica o interno, preceito de base da fisiognomonia, ciência que estuda o comportamento humano por meio dos indícios do corpo, existente desde a Antiguidade, mas que ganha fôlego justamente nos momentos históricos em que a identidade individual está em transformação: início do século XVı e final do XVII.

Essa primeira característica do conceito de fotogenia esconde a segunda e revela um paradoxo: a equiparação da capacidade fotogênica entre corpo humano e objetos. Epstein justapõe em sua analogia do close as lágrimas de um olho e um telefone tocando, a expressão de uma boca e o insert de um relógio de pulso. Se o rosto ou parte dele em close significam intensamente, o detalhe de um objeto também pode significar de maneira fulgurante. Mais tarde, Deleuze e Guattari (1989) falam do fenômeno de "rostificação" que atinge os objetos filmados: "um objeto no cinema será rostificado; podemos dizer que ele nos olha, não porque se parece com um rosto, mas porque se conecta à máquina abstrata da rostificação" (p. 214). Eisenstein e Edgar Morin escreveram linhas similares, ambos falando da chaleira de Griffith que "olha" o espectador.

A fotogenia se espalhou, portanto, como um rastilho de pólvora, visto que o cinema se tornou esse lugar de representação de afetos e do engrandecimento espiritual não só dos seres representados mas também dos espectadores. Para além de toda a crença do meio cinematográfico como revelador da essência do ser humano (“O cinema tem uma alma?", perguntou-se o teórico católico Henri Agel), o fato é que o close fotogênico acabou dominando não só a gramática clássica do cinema como também os produtos e objetos de outros meios (séries de televisão e telenovelas, reality shows, a linguagem jornalística). Até o teatro pós-moderno levou as câmeras ao palco para aproximar o espectador da expressão do ator e tirar daí proveitos narrativos e plásticos.

\section{Da fotogenia à sua perda}

Esse conceito inicial de fotogenia não esconde o paradoxo que o forma. O mesmo rosto que pode ter propriedades magicamente expressivas, revelar verdades e sentimentos escondidos no interior dos atores-personagens pode ser relegado ao estatuto de coisa e significar tanto quanto um pé, uma 
mão ou uma montanha. Daney (1981) chegou a dizer que alguns diretores como Manoel de Oliveira filmam "os atores como paisagem" (p. 38). Godard expressou posição similar defendendo a "paisagem como um rosto" no texto dito em Duas ou três coisas que eu sei dela. Nesse sentido, a quebra com o conceito de fotogenia afetiva e psicológica é essencial para se entender a maneira como o cinema moderno filma os rostos dos atores, subjugando-os às bordas do quadro (Antonioni), relegando-os ao fora de campo (Bresson, Oliveira), filmando-os no contraluz (Duras) ou apenas a parte posterior da cabeça (Godard). A ideia é que o rosto no cinema moderno, assim como no primeiro cinema, vale tanto quanto outros objetos ou alguma parte do corpo; a face deixa de ser o único local de afeto, pulsões, desejos e significação e se torna uma parte do corpo como outra qualquer.

A quebra da supremacia do rosto do ator como local de significação psicológica teve no cinema soviético dos anos 1920 sua melhor expressão. Ao analisar a obra teórica e cinematográfica de Lev Kulechov, lampolski propõe os termos "rosto-máscara" e "rosto-máquina", segundo os quais o trabalho dos atores pode ser identificado.

\section{Máquina: o excesso contra o naturalismo}

O rosto que atua como uma máquina é aquele que, embora anatômico, não se comporta segundo as leis da organicidade. É uma face que deixa de ser a expressão de sentimentos e afetos, que não mais é a exterioridade de uma interioridade em que o ator trabalha dentro de uma lógica de verossimiIhança e de representação realista e jogo naturalista. A repetição sistemática de movimentos corporais, sem embasamento psicológico, também faz parte da teoria do rosto-máquina, que pode contaminar o corpo como um todo.

Tanto o rosto-máquina como o rosto-máscara se pautam, segundo a apreciação de lampolski, pela recusa das expressões faciais orgânicas e da herança do jogo teatral no cinema. No entanto, embora sejam termos que veiculam a noção da quebra do naturalismo psicológico, a representação de um rosto-máquina pode ser diametralmente oposta à de um rosto-máscara. Se o rosto-máscara ganha significação justamente pela ausência de expressão específica, o rosto-máquina 
deve seguir um ritmo e uma métrica. [...] Kulechov propõe a ginástica facial, longe de qualquer motivação psicológica. O rosto é dissociado em elementos perfeitamente autônomos que se movem segundo as ordens do diretor como as partes de uma máquina, privado de qualquer objetivo ligado à expressão de um sentido ou sentimento. (IAMPOLSKI, 1994, p. 28)

O rosto-máquina mexe-se excessivamente; o máscara guarda sua imobilidade. Ambos fogem da zona de conforto do naturalismo, um pelo excesso do gesto, o outro pela sua rarefação. Para além dessas diferenças pontuais de representação, ambos se calcam sobre a luta contra toda necessidade expressiva de ordem psicológica. Kulechov dava bastante atenção aos movimentos dos olhos dos atores como uma maneira de tirar deles a função da visão e de transformá-los em "apêndice das mãos" (IAMPOLSKI, 1994, p. 28). Os movimentos das partes do rosto devem estar fora de sintonia uns com os outros; a boca diz uma coisa, os olhos dizem outra, e a expressão geral da face diz uma terceira. É como se cada parte atuasse de maneira independente, embora fossem ligadas umas às outras.

A concepção do rosto-máquina reaparece fortificada justamente pelo cinema moderno, que quebra com a suposta objetividade e espontaneidade do jogo do ator naturalista psicológico. Num dos filmes faróis da Nouvelle Vague, Acossado, o rosto-máquina aparece justamente no momento em que Jean-Paul Belmondo é alvejado por policiais e cai no meio da rua, nos minutos finais da trama. As expressões faciais do seu rosto desafiam qualquer tentativa de interpretação psicológica do gesto; nenhuma teoria psicológica do trabalho do ator poderia explicar os biquinhos, muxoxos e o gesto de fechar os próprios olhos, feitos pelo personagem que está à beira da morte.

Belmondo e Godard desafiam assim todas as mortes naturalistas do cinema, atingindo um dos preceitos mais inabaláveis do cinema clássico: a ideia da continuidade e da verossimilhança psicológica do jogo do ator.

\section{Máscara: permeabilidade de sentidos}

No outro lado da dicotomia em torno do rosto não naturalista, o rosto-máscara também pretende tirar o jogo da chave realista e psicológica, apostando na imobilidade e no abrandamento emocional. Para lampolski (1994), 
transformar o rosto em máscara significa transformá-lo em espelho, objetividade máxima. O rosto não mais reflete o que acontece no interior do organismo, mas volta sua reflexividade para o exterior. Vem daí sua capacidade de refletir movimentos do corpo e sua incapacidade de refletir movimentos da alma. (p. 33)

lampolski (1994) conta que Louis Delluc orientava seus atores para que procurassem um rosto de gesso, fazendo uso, se necessário, de cocaína, que "deixa os olhos com um estatismo estranho bem-vindo no cinema" (p. 30). O excesso de movimentos dos olhos do rosto-máquina e, por outro lado, seu aspecto vítreo no rosto-máscara resvalam em resultados parecidos: o esvaziamento do jogo, uma espécie de ausência de alma (e, portanto, de psicologismo) do ator que desloca a construção de sentidos para outras partes do seu corpo, do cenário ou da linguagem fílmica. Kulechov chamava os atores de "modelos" e dizia que objetos podem ser tão expressivos no cinema quanto corpos. "O aumento máximo do olho o transforma num objeto, num corpo e o desloca da sua função visual" (IAMPOLSKI, 1994, p. 30), enquanto Jean Epstein não via diferença entre o close de um olho ou de um revólver.

A máscara, não por acaso um elemento presente no teatro desde a Antiguidade, no cinema só vai adquirir significado na inscrição do rosto dentro da lógica do fluxo de significados presentes em outros elementos da imagem: enquadramentos, relação entre planos etc. lampolski resume o princípio da máscara como algo que obriga o corpo a assumir as funções de rosto e o rosto a se transformar em corpo e lembra que, nos anos 1910 e 1920, a máscara era associada à essência, e o rosto, à mentira. "A máscara é consubstancial da essência, pois ela reflete objetivamente" (IAMPOLSKI, 1994, p. 33). Para ele, o intuito de Kulechov com as teorias do rosto-máquina e máscara era se opor ao rosto-expressão (elemento essencial da empatia/identificação entre ator e espectador) e ao rosto-personalidade (pedra de toque do star system, a individualidade da estrela que migra de papel para papel).

Na teoria do rosto-máquina, a face age segundo as leis do corpo, especialmente a da independência de seus membros; na do rosto-máscara, a face, conservando sua imobilidade, reflete como um espelho os movimentos do corpo - ou não reflete nada. No cinema, ao contrário do teatro, uma particularidade do meio da expressão, a montagem, está a serviço dessa reflexividade 
mecânica. É de um efeito de montagem que surge a maior manifestação do rosto-máscara de que se tem ideia no cinema: o efeito Kulechov. Experiência de montagem que algumas fontes históricas não imputam diretamente a Kulechov, mas a seus alunos, o efeito K. mostra um rosto de ator com expressão neutra, uma face desprovida de qualquer leitura ou interpretação prévia, uma superfície branca, esvaziada de significados e que só vai adquiri-los no contexto da montagem - que alterna o plano do ator com imagens anódinas, uma criança morta, uma mulher seminua, um prato de comida. Reivindica-se que, a partir dessa junção de elementos díspares, possa-se ler no rosto do ator feições de sentimentos como pena, desejo sexual ou fome. O efeito Kulechov é a "transformação de um rosto-máscara em rosto-expressão através da montagem" (IAMPOLSKI, 1994, p. 31). A emergência de um ou diversos sentidos ligados à colagem de planos é um dos alicerces da linguagem cinematográfica e está presente em todos os tipos de cinema, do soviético ao mainstream americano.

O rosto-máscara cai em desuso no cinema clássico hollywoodiano, no qual a fotogenia, o rosto-expressão (o ator se expressando de dentro para fora) e o rosto-personalidade (ligado à individualidade do intérprete e ao uso do ator-mercadoria, noção desenvolvida por Edgar Morin) são as regras. Porém, o cinema clássico e o moderno tematizaram e problematizaram a forma das máscaras. Olhos sem rosto, $A$ outra face e $A$ pele que habito, por exemplo, tocam na questão da identidade ligada às particularidades do rosto ou da própria face humana funcionando com uma máscara. No campo do uso da máscara como elemento formal, Rainer Werner Fassbinder e Robert Bresson transformam o rosto do ator numa superfície que por si nada significa, extirpam da face dos intérpretes a possibilidade de que ela seja local da expressão dos afetos e sentimentos. Na obra desses cineastas, os efeitos de montagem, o enquadramento e até outras partes do corpo ressignificam o rosto. $\mathrm{O}$ jogo do ator passa a não valer nada por si só, mas apenas inscrito dentro de uma lógica de outras significações.

\section{A tela não reflete a alma}

Esse uso no cinema moderno da interpretação neutra, esvaziada de naturalismo, desencadeia a última diferenciação proposta neste trabalho: a do 
rosto-alma e rosto-tela, proposta por Jacques Aumont. Essa dicotomia apoia-se nos mesmos princípios que opõem a máquina e a máscara à expressão e à personalidade do rosto. Tela e alma aplicadas ao rosto são conceitos mais frontalmente opostos que máquina e máscara. Aumont ataca principalmente a ideia de que a tela do cinema pode receber e projetar visões de mundo e pulsões emitidas pelo espectador. Se a tela do cinema clássico é absorvente, a do cinema moderno é repelente e perde a capacidade de refletir a alma de quem se coloca na frente dela.

Os objetos de Aumont são os rostos das atrizes de $A$ paixão de Joana d'Arc, Viver a Vida e Persona. Para ele, os dois primeiros filmes tratam os rostos das atrizes (Maria Falconetti e Anna Karina) de maneiras similares, "feitos para tornar visível a desesperante e essencial nudez da alma, o rosto da alma" (AUMONT, 1992, p. 10). O rosto de Falconetti é explorado à exaustão pela câmera de Dreyer e se cola ao de Anna Karina no filme de Godard, num efeito de montagem, para deixar claro o furacão interior que move essas duas personagens, condenadas à incompreensão e, mais tarde, à morte. Os movimentos do rosto de ambas são usados para expressar semiologicamente a interioridade do personagem. Joana d'Arc e Nana são ligadas por um close fotogênico, em que o exterior do corpo do ator expressa sentimentos ou emoções construídas internamente. Num arroubo anticlerical, Godard parece nos dizer que o sacrifício da prostituta moderna é similar ao da santa mártir da história francesa. Em seu cinema de rostos superficiais como o de Belmondo, esse tipo de plano fotogênico, um dos alicerces do jogo naturalista, faz figura de exceção; ele funciona como uma homenagem explícita aos fundamentos do cinema norte-americano clássico no que diz respeito ao jogo dos atores que tanto encantou o jovem crítico Hans Lucas. $\mathrm{O}$ ator godardiano por excelência será mais o Belmondo de Acossado ou o Jean-Pierre Léaud de A chinesa, opacos e despedaçados, do que a inteireza espiritual de Anna Karina em Viver a vida.

Aumont se pergunta se uma alma pode falar a outra alma. De Falconetti a Anna Karina e de Anna Karina ao espectador. Da humanidade de um rosto à humanidade de outro rosto, como defenderam os teóricos do dispositivo fílmico como elo entre ator na tela e espectador na sala (Baudry, Metz, Comolli). Aumont (1992), no entanto, questiona sua hipótese e sentencia que a alma se tornou uma noção duvidosa. "Foi onde ela foi o valor mais eminente, 
no cinema de arte europeu, que ela foi mais colocada em cheque" (p. 10). Se existe uma tese para o pensamento de Aumont, seria "de tanto se deixar olhar, perde-se a face" (AUMONT, 1992, p. 11), e essa perda é resumida nos cinco anos que separam o filme de Godard do de Bergman.

O título do filme de Bergman, um termo que evoca justamente as máscaras do teatro antigo e é usado para falar da imagem pública do ator, revela do que se trata sua fábula. "Persona é meramente uma história de máscaras, sem alma por trás que escondesse a verdade. A 'verdade' é um pano fluido que passa de rosto em rosto sem jamais parar em um só" (AUMONT, 1992, p. 11).

No prólogo do filme, antes que a fábula comece de maneira narrativa propriamente dita, um garoto aparentemente com problemas de visão toca em dois rostos femininos gigantescos, como se quisesse "dar uma alma a esses rostos gigantes. No final, ele ainda toca, mas os rostos não param de escapar dele" (AUMONT, 1992, p. 11). Para o autor, Persona é a explicação desses rostos, mas o filme só explica isto:

O rosto é uma tela, uma superfície. Não há nada por trás dele e o que se inscreve nele lhe é estranho. Poderia ter se inscrito em outro lugar, num outro rosto ou esses rostos poderiam se completar, se sobrepor, se grudar como superfícies indiferentes. (p. 11)

A interpretação de Aumont vai contra uma série de análises feitas sobre o filme de Bergman e sobre a obra do cineasta como um todo, na qual as ações dos atores teriam necessariamente fundamentos psicológicos - quiçá psicanalíticos - bastante pronunciados e bem definidos. Na contramão dos teóricos da psicologia cinematográfica, Aumont defende que para Bergman, pelo menos nesse filme, o rosto das suas atrizes Bibi Andersson e Liv Ullmann é material puramente plástico, que como tal pode ser tocado, manipulado, escavado e aglutinado num só rosto. Para além do vampirismo ou da questão do duplo que rondam a história da atriz e sua enfermeira, está a possibilidade de brincar com o rosto fotogênico e transformá-lo em rosto monstruoso que parece justificar toda a construção narrativa de Persona. $O$ plano da junção dos rostos demonstra apenas isso: que o cineasta quis dar uma de artista plástico e criar um ser enigmático e monstruoso, que flerta mais com Picasso do que com Freud. 


\section{Referências bibliográficas}

AUMONT, J. Du visage au cinema. Paris: Cahiers du Cinéma, 1992.

COURTINE, J.-J.; HAROCHE, C. Histoire du visage. Paris: Payot et Rivages, 2007.

DANEY, S. Que peut un cœur? Cahiers du Cinéma, Paris, n. 330, p. 36-39, dez. 1981.

DELEUZE, G.; GUATTARI, F. Mille Plateaux. Paris: Editions de Minuit, 1989.

EPSTEIN, J. Magnification and other writings. October, v. 3, p. 9-25, primavera 1977. IAMPOLSKI, M. Visage-masque et visage-machine. In: ALBERA, F. (Org.). Vers une théorie de l'acteur. Lausanne: L'Age d'Homme, 1994. p. 35-40.

\section{Referências fillmográficas}

Acossado. Direção: Jean-Luc Godard. França, 1960. 90 minutos.

A outra face. Direção: John Woo. Estados Unidos, 1997. 138 minutos.

A paixão de Joana d'Arc. Direção: Carl Theodor Dreyer. Dinamarca, 1928. 110 minutos.

A pele que habito. Direção: Pedro Almodóvar. Espanha, 2011. 120 minutos.

Cleópatra. Direção: Júlio Bressane. Brasil, 2007. 116 minutos.

Duas ou três coisas que eu sei dela. Direção: Jean-Luc Godard. França, 1967. 87 minutos.

Educação sentimental. Direção: Júlio Bressane. Brasil, 2013. 84 minutos.

Olhos sem rosto. Direção: Georges Franju. França, 1960. 88 minutos.

Persona. Direção: Ingmar Bergman. Suécia, 1966. 85 minutos.

Viver a vida. Direção: Jean-Luc Godard. França, 1962. 83 minutos.

Recebido em 24/07/2015

Aprovado em 08/10/2015

Publicado em 21/12/2016 